\title{
Physicochemical profile of commercial margarines marketed in Brazil and the impact of trans fatty acid elimination
}

\author{
Thaís Silva $^{1}$, Daniel Arellano ${ }^{2}$, and Ana Paula Bada Ribeiro ${ }^{1}$ \\ ${ }^{1}$ Universidade Estadual de Campinas \\ ${ }^{2}$ University of Campinas
}

May 6, 2020

\begin{abstract}
This study aimed to evaluate the physicochemical composition, the lipid profile, and the technological and nutritional impact of Brazilian margarines. Thirteen margarine samples were characterized for fatty acid composition, technological properties, and thermal stability. The margarines presented total fat from 20 to $82 \%$ and low trans fatty acids (TFA) levels, except for two samples (5-7\% of elaidic acid), allowing labels to declare "zero trans-fat", according to the current Brazilian legislation (Resolution 54 of November 12, 2012). All margarines had similar fatty acids composition, with predominance of linoleic (23$46 \%$ ), oleic (20-46\%) and palmitic acids (7-14\%), probably from soy and palm-based fats. The saturated fat content ranged from 23 to $31 \%$. All lipid phases had a similar fat solid profile, with a melting point between 22 and $28{ }^{\circ} \mathrm{C}$. The margarines with higher lipid content and saturated fatty acids (SFA) showed greater hardness and lower spreadability, and the presence of TFA provided greater plasticity. Changes in the lipid profile of this product are still necessary, as there is a global transition scenario aimed at healthy aspects with the elimination of TFA and reduction of SFA intake to reduce deaths from coronary heart disease.
\end{abstract}

\section{Hosted file}

Manuscript.pdf available at https://authorea.com/users/318183/articles/448112physicochemical-profile-of-commercial-margarines-marketed-in-brazil-and-the-impactof-trans-fatty-acid-elimination 

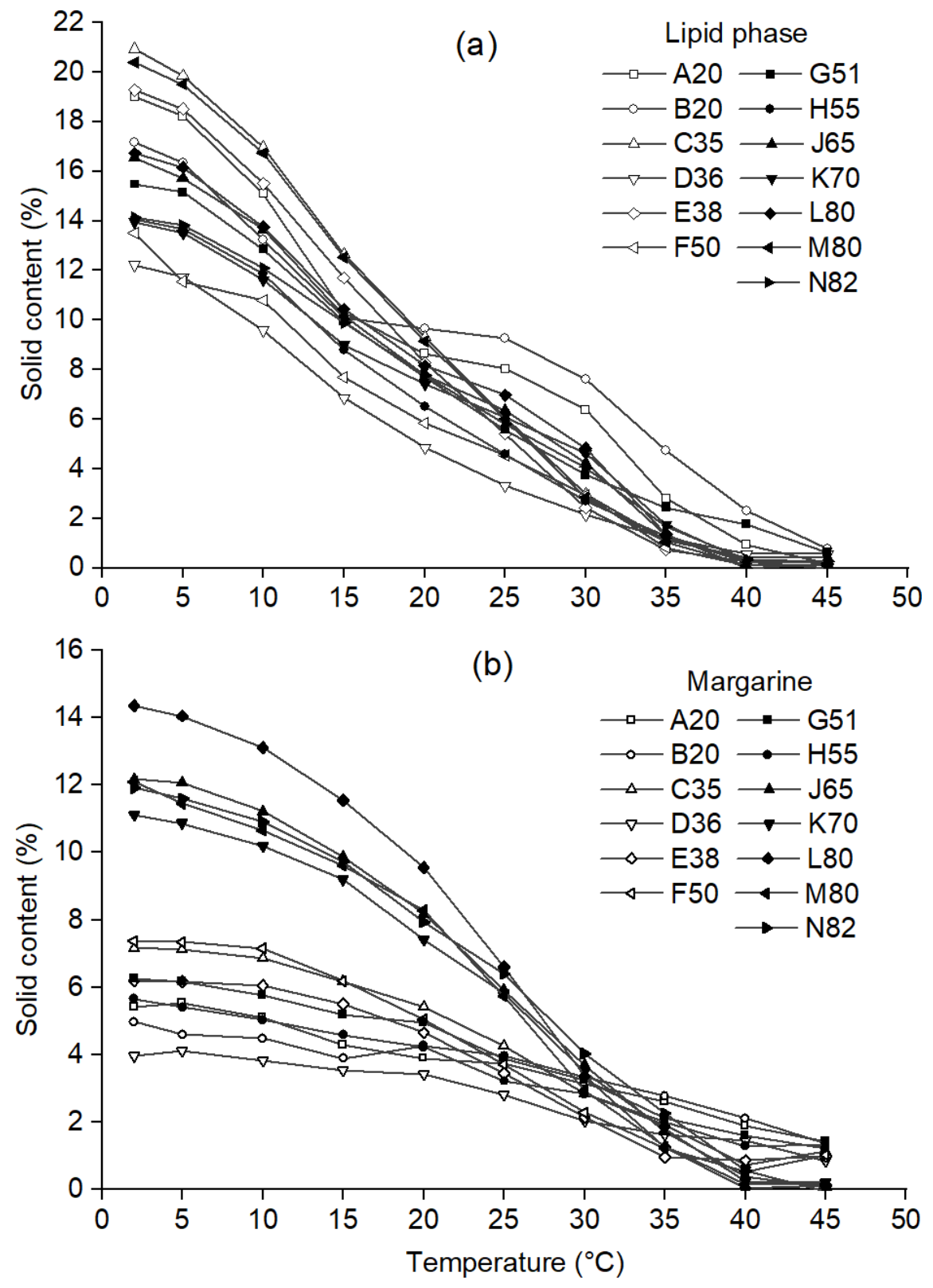

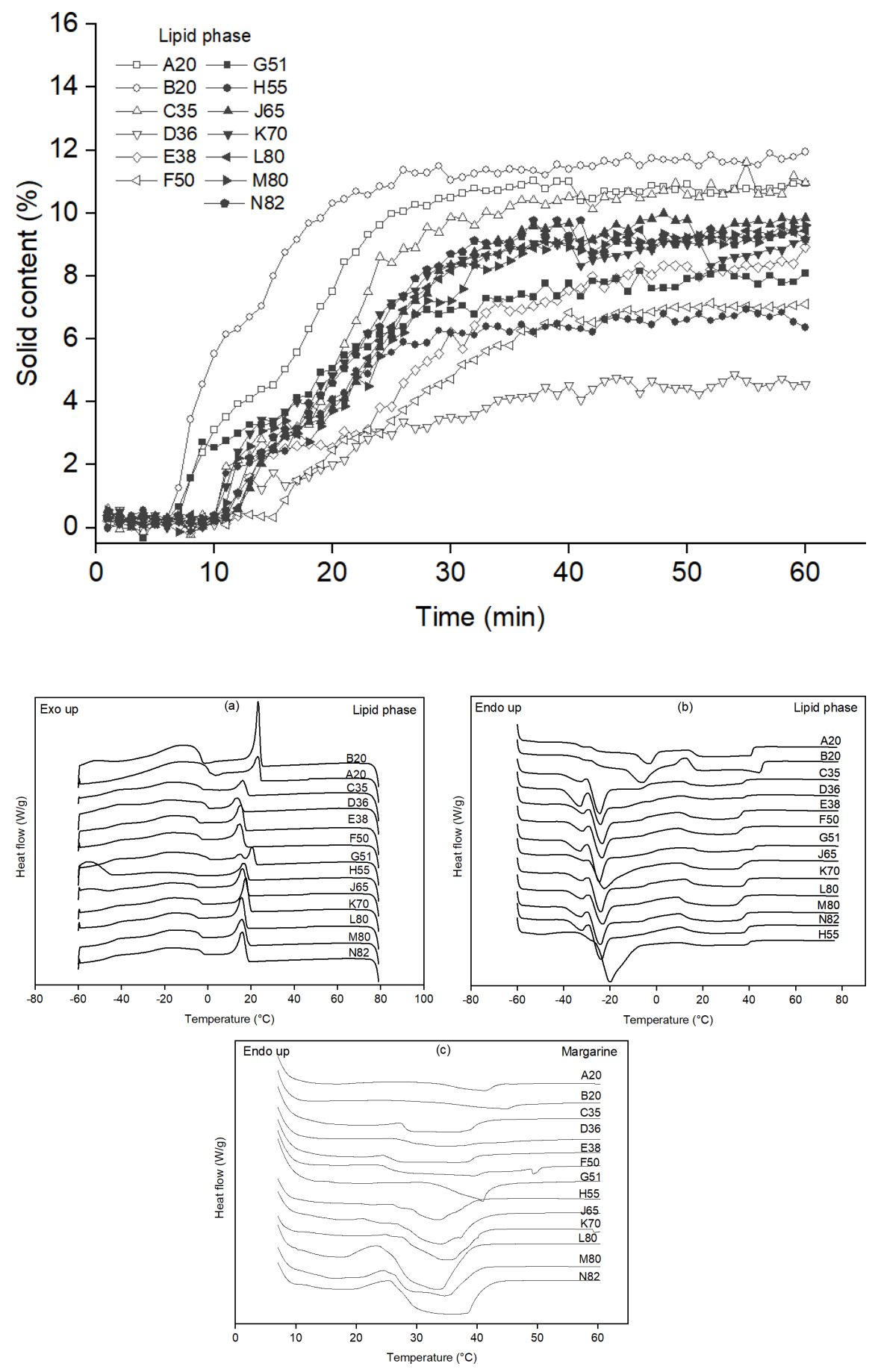

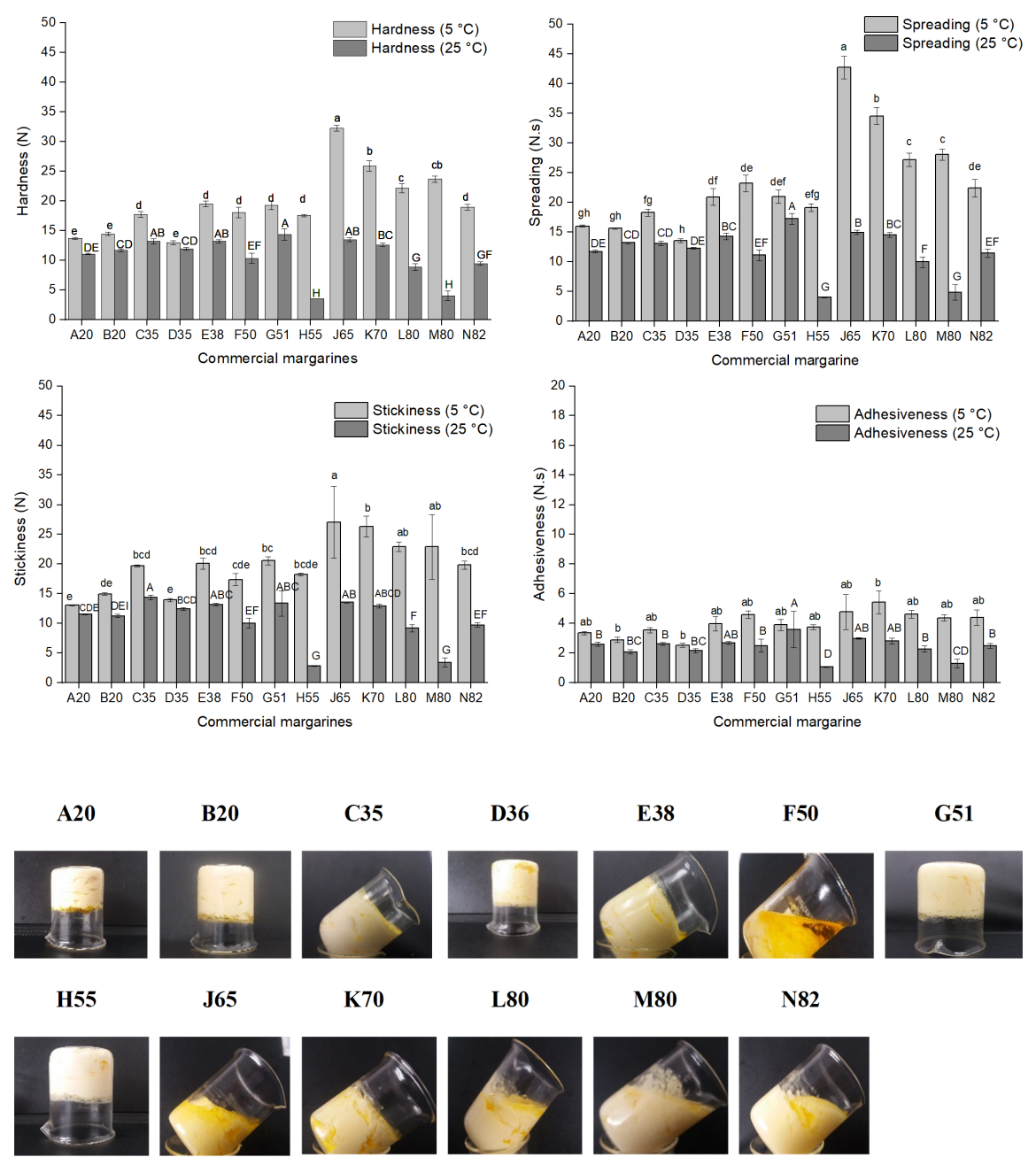